\section{Cuadernos de \\ Investigación \\ Histórica}

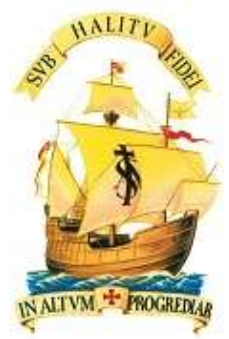

Cuadernos de Investigación Histórica $\mathrm{N}^{\mathrm{o}} 35$ HOMENAJE A SANTO TOMÁS DE VILLANUEVA Año: 2018

DOI: https://doi.org/10.51743/cih.78

\title{
VIGENCIA ACTUAL DE LA TEOLOGÍA DE LA CARIDAD DE SANTO TOMÁS DE VILLANUEVA
}

\author{
CURRENT VALIDITY OF THE THEOLOGY OF CHARITY OF SAINT \\ THOMAS OF VILLANUEVA
}

JOZEF RŽONCA

Facultad de Teología de la Universidad de Trnava

\begin{abstract}
Resumen
Este trabajo presenta una lectura sincrónica de la caridad en la obra de Santo Tomás de Villanueva desde a la luz de la encíclica Deus caritas est del Papa Benedicto XVI que ofrece líneas básicas para la teología contemporánea de la caridad. En el desarrollo del trabajo, en primer lugar, se identifican los puntos clave de esta encíclica; en segundo lugar, se presentan algunos acentos de la teología de la caridad de Santo Tomás de Villanueva desde la perspectiva de la primera encíclica del Papa emérito; y, por último, se presentan unas conclusiones acerca de la vigencia que tienen en la actualidad los fundamentos dela teología del santo agustino.
\end{abstract}

Palabras clave: Santo Tomás de Villanueva, deus caritas est, Benedicto VXI, caridad 


\begin{abstract}
This work presents a synchronic reading of charity in the work of Santo Tomás de Villanueva from the light of the encyclical Deus caritas est by Pope Benedict XVI that offers basic lines for the contemporary theology of charity. In the development of the work, in the first place, the key points of this encyclical are identified; secondly, some accents of the theology of charity of Santo Tomás de Villanueva are presented from the perspective of the first encyclical of the Pope Emeritus; and, finally, some conclusions are presented about the validity that the foundations of the theology of the Augustinian saint have today.
\end{abstract}

Keywords: Saint Thomas of Villanueva, Deus caritas est, Benedict XVI, charity

$\mathrm{S}_{\mathrm{n}}^{\mathrm{o}}$ obre la teología de la caridad en la predicación de santo Tomás de Villanueva (1486-1555) ya se dedicaron varios autores, entre los que habría que recordar al P. Argimiro Turrado ${ }^{1}$, que refleja la caridad, en el pensamiento de este santo, como esencia de la vida espiritual, basándose en el modelo psicológico de la Trinidad, típico de la herencia agustiniana ${ }^{2}$.

Dado de que la reflexión teológica después del Concilio Vaticano II aportó nuevos acentos teológicos ${ }^{3}$, parece útil ver el tema desde la óptica de la teología contemporánea. Por ello, hemos decidido realizar una lectura sincrónica de la caridad en la obra de santo Tomás de Villanueva desde el prisma de la primera encíclica del papa Benedicto XVI Deus caritas est (2005), ${ }^{4}$ que ofrece líneas básicas para la teología contemporánea de la caridad.

El desarrollo de nuestro trabajo lo realizaremos en tres pasos. En primer lugar, vamos a identificar los puntos clave de la encíclica de Benedicto XVI, que nos van a servir para el segundo paso, en el que propiamente analizaremos de la obra de santo Tomás de Villanueva. En esta parte no nos centramos solamente

\footnotetext{
${ }^{1}$ TURRADO, A.: La teología de la Caridad en Santo Tomás de Villanueva, maestro de espiritualidad agustiniana. In: Ciudad de Dios 171 (1958): 564-598.

${ }^{2}$ Cfr. AGUSTÍN, De Trinitate, XV 18, 32.

${ }^{3}$ El Concilio Vaticano II, en su esfuerzo renovador, dirigió su atención hacia los signos de los tiempos y proclamó la obligación de cada creyente de leer estos signos a la luz de la Palabra de Dios (GS 11 y 44). Rino Fisichella, en los documentos del Concilio, identifica los siguientes signos de los tiempos: el esfuerzo por la santidad personal (LG 39-42), la libertad religiosa (DH 15), el respeto a la dignidad humana (GS 63-72), el acento en la dimensión testimonial de la vida cristiana (LG 42), el esfuerzo por la paz (GS 77-90) y las tendencias para construir formas culturales más humanas (GS 53-62). FISICHELLA, R.: Quando la fede pensa. Casale Manteferrato, 1997, 310 p. ISBN 978- 8838-429-507.

${ }^{4}$ BENEDICTO XVI: Carta enciclica Deus caritas est: Sobre el amor cristiano. Madrid, 2006, 87 p. ISBN 84-8239-997-7.
} 
en la descripción tomasina de la caridad, sino que también buscaremos los puntos de convergencia o divergencia con la doctrina contemporánea presente en dicha encíclica del papa emérito. El tercer y último paso, lo dedicaremos a la conclusión.

\section{CLAVE HERMENÉUTICA: LA ENCÍCLICA DEUS CARITAS EST}

La encíclica Deus caritas representa una clave hermenéutica del magisterio de Benedicto XVI, que presenta la historia de la Iglesia como la historia de la caridad. ${ }^{5}$ El texto consta de dos partes principales. En la primera, más teórica, Benedicto XVI se enfoca en el concepto de amor, y en la segunda, más práctica, hacia la práctica del amor al prójimo en el ambiente de la Iglesia. ${ }^{6}$

Como ya hemos dicho, nuestro fin no es presentar un resumen de la encíclica Deus caritas est, ni tampoco hacer un análisis de la misma, sino identificar temas que nos sirvan después para examinar la vigencia de la teología de la caridad de santo Tomás de Villanueva.

Al principio de la encíclica, el papa Benedicto XVI habla sobre la esencia del amor y muestra la diferencia entre "eros", "philia" y "agapé".

"Nuestras reflexiones sobre la esencia del amor, inicialmente bastante filosóficas, nos han llevado por su propio dinamismo hasta la fe bíblica. Al comienzo se ha planteado la cuestión de si, bajo los significados de la palabra amor, diferentes e incluso opuestos, subyace alguna unidad profunda o, por el contrario, han de permanecer separados, uno paralelo al otro. Pero, sobre todo, ha surgido la cuestión de si el mensaje sobre el amor que nos han transmitido la Biblia y la Tradición de la Iglesia tiene algo que ver con la común experiencia humana del amor, o más bien se opone a ella. A este propósito, nos hemos encontrado con las dos palabras fundamentales: eros como término para el amor «mundano» y agapé como denominación del amor fundado en la fe y plasmado por ella. Con frecuencia, ambas se contraponen, una como amor «ascendente», y como amor «descendente» la otra. Hay otras clasificaciones afines, como, por ejemplo, la distinción entre amor posesivo y amor oblativo (amor concupiscentiae - amor benevolentiae), al que a veces se añade también el amor que tiende al propio provecho. A menudo, en el debate fi-

\footnotetext{
${ }^{5}$ Cfr. "La prima Enciclica di Papa Benedetto XVI tratta un tema che permette di ripercorrere tutta la storia della Chiesa, che è anche storia di carità. È una storia di amore ricevuto da Dio, che va portato al mondo: [...]" FRANCISCO: Discorso del santo padre Francesco al participanti al congresso internationale sull'Enciclica Deus Caritas est di Benedetto XVI, nel decimo anniversario della pubblicazione. 26-2-2016, [on-line] https://w2.vatican.va/content/francesco/it /speeches/2016/february/documents/papa-francesco_20160226_congresso-deus-caritas-est.html [cit 20-12-2017].

${ }^{6}$ BENEDICTO XVI: Encíclica Deus caritas est, n. 1.
} 
losófico y teológico, estas distinciones se han radicalizado hasta el punto de contraponerse entre sí: lo típicamente cristiano sería el amor descendente, oblativo, el agapé precisamente; la cultura no cristiana, por el contrario, sobre todo la griega, se caracterizaría por el amor ascendente, vehemente y posesivo, es decir, el eros[...] En realidad, eros y agapé — amor ascendente y amor descendente - nunca llegan a separarse completamente."7

Benedicto XVI rehúye de cualquier forma de reduccionismo. El hombre no puede vivir solamente con el amor ascendente, que se dona. Si quiere dar, también tiene que recibir. Si quiere donar, también tiene que aprender a recibir. Ambos amores (amor ascendente y amor descendente) son complementarios, pero tienen una clara jerarquía, $\mathrm{y}$, gracias a ella, el hombre transciende su dimensión meramente biológica ${ }^{8}$, se libera de su autosuficiencia ${ }^{9}$, se abre a la comunidad y descubre la meta de su vida y la plenitud de su propia existencia. ${ }^{10}$

La vocación de un cristiano es crear una síntesis bien ordenada del amor ascendente y descendente, síntesis de la comprensión antropológica y teológica del amor, respetando la vocación que uno va descubriendo en el acto de fe en el Hijo de Dios, que, al fin y al cabo, se manifiesta en su imitación. Uno de los medios para expresar dicha síntesis de los diferentes tipos de amor, del dar y recibir, es la actitud solidaria y el comportamiento caritativo.

"Ciertamente, el amor es «éxtasis», pero no en el sentido de arrebato momentáneo, sino como camino permanente, como un salir del yo cerrado en sí mismo hacia su liberación en la entrega de sí y, precisamente de este modo, hacia el reencuentro consigo mismo, más aún, hacia el descubrimiento de Dios: «El que pretenda guardarse su vida, la perderá; y el que la pierda, la recobrará» (Lc 17, 33), dice Jesús en una sentencia suya que, con algunas variantes, se repite en los Evangelios (cf. Mt 10, 39; 16, 25; Mc 8, 35; Lc 9, 24; Jn 12, 25). Con estas palabras, Jesús describe su propio itinerario, que a través de la cruz lo lleva a la resurrección: el camino del grano de trigo que cae en tierra y muere, dando así fruto abundante."11

\footnotetext{
${ }^{7}$ BENEDICTO XVI: Encíclica Deus caritas est, n. 7.

${ }^{8}$ Cfr. BENEDICTO XVI: Encíclica Deus caritas est, n. 5.

9 "En oposición al amor indeterminado y aún en búsqueda, este vocablo expresa la experiencia del amor que ahora ha llegado a ser verdaderamente descubrimiento del otro, superando el carácter egoista que predominaba claramente en la fase anterior. Ahora el amor es ocuparse del otro y preocuparse por el otro. Ya no se busca a sí mismo, sumirse en la embriaguez de la felicidad, sino que ansía más bien el bien del amado: se convierte en renuncia, está dispuesto al sacrificio, más aún, lo busca. " BENEDICTO XVI: Encíclica Deus caritas est, n. 6.

10 "El amor engloba la existencia entera y en todas sus dimensiones, incluido también el tiempo. No podría ser de otra manera, puesto que su promesa apunta a lo definitivo: el amor tiende a la eternidad." BENEDICTO XVI: Encíclica Deus caritas est, n. 6.

${ }^{11}$ BENEDICTO XVI: Encíclica Deus caritas est, n. 6.
} 
El amor, en sus formas concretas -expresado como misericordia o como solidaridad- es, más que un deber, una forma de salida de sí mismo para salir al paso de otro, es decir, debería ser más una forma de altruismo, en el que uno encuentra su identidad.

El amor es el garante de que toda la actividad humana hacia los demás no sea un instrumento exánime, deshumanizado, sino una actitud basada en la presencia personal, en la que se reconoce a Cristo, que se humilló a sí mismo para elevarnos de la miseria a la dignidad de hijos de Dios ${ }^{12}$. Ahora bien, el verdadero amor, que se concreta en la acción externa personal e interpersonal, implica el respecto de la dignidad de todas las partes involucradas.

"La actuación práctica resulta insuficiente si en ella no se puede percibir el amor por el hombre, un amor que se alimenta en el encuentro con Cristo. La íntima participación personal en las necesidades y sufrimientos del otro se convierte así en un darme a mí mismo: para que el don no humille al otro, no solamente debo darle algo mío, sino a mí mismo; he de ser parte del don como persona." $" 13$

Aunque el fundamento del amor es Dios - que es Amor-, este amor no está separado de la dimensión histórica de la existencia humana y de la revelación. Por lo tanto, es imprescindible hablar de la pluridimensionalidad de las manifestaciones del amor, de su concreción ${ }^{14}$. Esta realidad remite a la creatividad de amor. $^{15}$

"La historia de amor de Dios con Israel consiste, en el fondo, en que Él le da la Torah, es decir, abre los ojos de Israel sobre la verdadera naturaleza del hombre y le indica el camino del verdadero humanismo. Esta historia consiste en que el hombre, viviendo en fidelidad al único Dios, se experimenta a sí mismo como quien es amado por Dios y descubre la alegría en la verdad y en la justicia; la alegría en Dios que se convierte en su felicidad esencial: «¿No te tengo a ti en el cielo?; y contigo, ¿qué me importa la tierra?... Para mí lo bueno es estar junto a Dios» (Sal 73 [72], 25. 28)."16

\footnotetext{
12 "Cristo ocupó el último puesto en el mundo - la cruz-, y precisamente con esta humildad radical nos ha redimido y nos ayuda constantemente." BENEDICTO XVI: Encíclica Deus caritas est, n. 35.

${ }^{13}$ BENEDICTO XVI: Encíclica Deus caritas est, n.34.

14 "[...] en el fondo, el " amor " es una única realidad, si bien con diversas dimensiones; según los casos, una u otra puede destacar más. Pero cuando las dos dimensiones se separan completamente una de otra, se produce una caricatura o, en todo caso, una forma mermada del amor." BENEDICTO XVI: Encíclica Deus caritas est, n. 8.

${ }^{15}$ BENEDICTO XVI: Encíclica Deus caritas est, n.31. - El texto señala la acción caritativa como una respuesta a una necesitad concreta.

${ }^{16}$ BENEDICTO XVI: Encíclica Deus caritas est, n.9.
} 
En este contexto, Benedicto XVI habla de corazones perceptivos o atentos $^{17}$. El corazón, en la tradición agustiniana, de la que Benedicto XVI es un buen conocedor ${ }^{18}$, no significa otra cosa que el interior del hombre. La atención o la percepción apunta hacia la dimensión dialógica. Aquí, se insinúa el espacio para la conciencia, en la que el hombre escucha la palabra de Dios, responde a ella y concluye consecuencias para su vida.

Un último elemento hermenéutico que querríamos resaltar en la encíclica Deus caritas est, es el criterio inspirador del amor, expresión que el autor ve en las palabras de la segunda carta a los Corintios: "Caritas Christi urget nos" $(5,14)$. La implicación de este criterio es clara: "La conciencia de que, en Él, Dios mismo se ha entregado por nosotros hasta la muerte, tiene que llevarnos a vivir no ya para nosotros mismos, sino para Él y, con Él, para los demás." 19 Este criterio libera a los creyentes de una moral legalista y los abre a la creatividad basada en la experiencia personal con Cristo viviente, en la fuerza de la gracia aceptada, en la fuerza del Espíritu Santo. ${ }^{20}$

De la encíclica resulta, que el amor, más que una deuda, es el don, con una característica principal: el compartir. Benedicto XVI en la siguiente carta encíclica Caritas in veritate dice: "La caridad es amor recibido y ofrecido. Es "gracia» (cháris). Su origen es el amor que brota del Padre por el Hijo, en el Espíritu Santo. Es amor que desde el Hijo desciende sobre nosotros. Es amor creador, por el que nosotros somos; es amor redentor, por el cual somos recreados. Es el Amor revelado, puesto en práctica por Cristo (cf. Jn 13,1) y «derramado en nuestros corazones por el Espíritu Santo» (Rm 5,5). Los hombres, destinatarios del amor de Dios, se convierten en sujetos de caridad, llamados a hacerse ellos mismos instrumentos de la gracia para difundir la caridad de Dios y para tejer redes de caridad." 21

\footnotetext{
${ }^{17} \mathrm{Cfr}$. "El programa del cristiano - el programa del buen Samaritano, el programa de Jesús- es un "corazón que ve». Este corazón ve dónde se necesita amor y actúa en consecuencia. Obviamente, cuando la actividad caritativa es asumida por la Iglesia como iniciativa comunitaria, a la espontaneidad del individuo debe añadirse también la programación, la previsión, la colaboración con otras instituciones similares." BENEDICTO XVI: Encíclica Deus caritas est, n.31.

${ }^{18}$ WALDENFELS, H.: Základni rysy teologie Benedikta XVI. In: Teologické texty 18 (2007), p. 59-63. ISSN 0862-6944.

${ }^{19}$ BENEDICTO XVI: Encíclica Deus caritas est, n. 33.

20 "Quien es capaz de ayudar reconoce que, precisamente de este modo, también él es ayudado; el poder ayudar no es mérito suyo ni motivo de orgullo. Esto es gracia. [...] Nosotros le ofrecemos nuestro servicio sólo en lo que podemos y hasta que Él nos dé fuerzas. Sin embargo, hacer todo lo que está en nuestras manos con las capacidades que tenemos, es la tarea que mantiene siempre activo al siervo bueno de Jesucristo: «Nos apremia el amor de Cristo» (2 Co 5, 14)." BENEDICTO XVI: Encíclica Deus caritas est, n. 35.

${ }^{21}$ BENEDICTO XVI: Encíclica Deus caritas est, n. 5 .
} 
El don del amor fundamentado en la Verdad revelada es el recurso esencial para la humanización de las relaciones interpersonales y para la superación de las estructuras del pecado, las cuales adquieren su expresión concreta en las distintas formas de pobreza, en el consumismo, en la alienación o en la pérdida del sentido de la vida.

\section{LA CARIDAD, SEGÚN SANTO TOMÁS DE VILLANUEVA}

Ahora bien, después de identificar los puntos clave en la encíclica Deus caritas est, que nos sirven como prisma para evaluar la actualidad de la doctrina de santo Tomás de Villanueva, podemos ver el modo como este santo refleja el tema de la caridad en sus sermones. A continuación, vamos a dedicarnos a los siguientes temas: (1) el fundamento de la teología de la caridad; (2) el amor que motiva la acción cristiana; (3) el corazón como el lugar de encuentro del hombre con el amor; (4) la manifestación del amor; (5) el amor y la creatividad.

\section{Fundamento de la teología de la caridad}

En la teología de la caridad de santo Tomás de Villanueva podemos identificar un trípode: la justicia conmutativa, la solidaridad descendente, y la solidaridad como respuesta a la experiencia con el amor de Dios.

\section{A. Justicia conmutativa:}

"En primer lugar, el hombre debe ser justo frente al prójimo en el reparto de los recursos temporales. Porque, como asegura Ambrosio en su libro sobre «Los deberes», la naturaleza lo hizo todo común, y este mundo no es otra cosa que una especie de heredad perteneciente a todos los hombres, aunque el derecho positivo haya establecido la propiedad privada, dando lugar a lo mío y lo tuyo entre los pueblos.",22

\section{B. Solidaridad del Hijo de Dios con la humanidad:}

"Pero ahora, cuando has compartido mi hambre, mi desnudez, mis trabajos, mis dolores y mi fragilidad, no eres ya un desconocido para los malos,

\footnotetext{
22 "Oportet primo ut homo sit iustus ad proximum in distributione temporalium, nam, ut ait Ambrosius in libro De officiis, natura omnia fecit communia, et hic mundus non est nisi quasi quaedam communis hereditas omnium, sed iure positivo appropriata sunt in particulari et locum habet in populis meum et tuum." VILLANOVA, T: Concio 174: Dominica quarta post Pascha, In: Manrique L. (ed.). Obras completas IV. Madrid 2012, p. 284.
} 
aprendiste a socorrer a los desdichados. Lo recuerda el Apóstol: «Por las cosas que padeció, aprendió la obediencia» (Heb 5,8), a tener compasión.”,23

\section{c. Solidaridad como respuesta de la praxis cristiana a la experiencia del amor de Dios:}

"En tres principalísimas razones se apoya el Apóstol para inculcarnos la obligación del amor recíproco: primera, porque somos miembros de un mismo cuerpo (Rom 12,5); segunda, porque somos hijos de un mismo Padre; tercera, porque participamos de una sola mesa y comemos de un mismo pan (1Cor 10,17)." 24

Estas tres dimensiones del amor constituyen para santo Tomás de Villanueva un modelo ético-religioso de la vida social de los cristianos.

El primer elemento de la teología de la caridad (a. justicia conmutativa) remite a la naturaleza común, como criaturas de Dios. Esta referencia al origen común, que refleja el amor de Dios hacia sus criaturas, implica la solidaridad básica entre hermanos, la solidaridad entre la gente. Se manifiesta, sobre todo, en la distribución, en el compartir los bienes y, por lo tanto, en la justicia conmutativa. En el trasfondo está el concepto de dignidad humana y la exigencia de igualdad respecto a las condiciones sociales. Santo Tomás de Villanueva enseñaba la doctrina con el lenguaje de su época, que corresponde con lo que, en el lenguaje del siglo XX, enseñaban los padres conciliares en el Concilio Vaticano II en la constitución pastoral Gaudium et spes:

"Dios ha destinado la tierra y cuanto ella contiene para uso de todos los hombres y pueblos. En consecuencia, los bienes creados deben llegar a todos en forma equitativa bajo la égida de la justicia y con la compañía de la caridad. Sean las que sean las formas de la propiedad, adaptadas a las instituciones legítimas de los pueblos según las circunstancias diversas y variables, jamás debe perderse de vista este destino universal de los bienes. Por tanto, el hombre, al usarlos, no debe tener las cosas exteriores que legítimamente posee como exclusivamente suyas, sino también como comunes, en el sentido de que no le aprovechen a él solamen-

\footnotetext{
23 "Sed iam, postquam famem, nuditatem, labores, dolores meos et fragilitatem assumpsisti, non ignarus malis, miseris succurrere didicisti. Apostolus: Didicit ex his quae passus est, oboedientiam, ut misericors fieret." VILLANOVA, T: Concio 89: Feria quinta dominicae primae Quadragesimae, In: Manrique L. (ed.). Obras completas II. Madrid 2011, p. 688. „Accepit naturam meam; et ecce qui eramus opprobrium angelis, sumus facti eorum consortes." VILlanOVA, T: Concio 146: Feria IV Passionis, In: Manrique L. (ed.). Obras completas III. Madrid 2011, p. 690.

24 "Tres rationes potissimas tangit Apostolus propter quas debemus diligere ad invicem: prima, quia sumus unius corporis membra; secunda, quia sumus unius Patris filii; tertia, quia ad unam mensam sedemus et unum panem manducamus." VILLANOVA, T: Concio 181: De foedere Burgis, In: Manrique L. (ed.). Obras completas IV. Madrid 2012, p. 398.
} 
te, sino también a los demás. Por lo demás, el derecho a poseer una parte de bienes suficiente para sí mismos y para sus familias es un derecho que a todos corresponde. Es éste el sentir de los Padres y de los doctores de la Iglesia, quienes enseñaron que los hombres están obligados a ayudar a los pobres, y por cierto no sólo con los bienes superfluos." 25

Por su parte, Benedicto XVI, en su encíclica Caritas in veritate, recordaba que la justicia es inseparable de la caridad y constituye su camino primordial. ${ }^{26}$

El segundo elemento de la teología de la caridad (b. solidaridad del Hijo de Dios con la humanidad) trata de la kénosis del Hijo de Dios, el cual voluntariamente entró en comunión con la humanidad afectada por el pecado. Esta solidaridad tiene una función reveladora y soteriológica. Su dimensión reveladora da a conocer a Dios, que por amor se inclina hacia su creatura para solevantarla y llevarla a una relación más profunda, en que el hombre pueda transcender su naturaleza.

El tercer elemento de la teología de la caridad (c. solidaridad como respuesta de la praxis cristiana a la experiencia del amor de Dios) remite en plenitud al aspecto íntimo. Brota de la respuesta a la vocación cristiana y a la experiencia del amor sobrenatural. Expresiones como "miembros de un mismo cuerpo" (unionis corporis membra), "los hijos de un mismo Padre" (unius Patris filii) y "participamos una sola mesa y comemos de un solo pan" (unam mensam et unum panem), subrayan la unidad con Cristo y en Cristo, lo que implica la interpelación al amor mutua, a la solidaridad. Estas tres expresiones del amor ponen de manifiesto la comunión de vida de los hijos adoptivos de Dios. Así, forman una unidad orgánica en Cristo, visibilizada en la Iglesia. La conciencia de pertenecer a ella, que brota de este triple vínculo, es la motivación para realizar el "amor recíproco" (debemus diligere).

Santo Tomás de Villanueva, en línea con los Padres de la Iglesia (san Agustín, san Juan Crisóstomo...), desarrolla la idea de la caridad-solidaridad en base a la identificación de la gente necesitada con Cristo: "Decía Crisóstomo: Él se transfigura en los pobres, para que no te dé vergüenza de dar poco [...]"27.

\footnotetext{
${ }^{25}$ GS 69.

26 “La caridad va más allá de la justicia, porque amar es dar, ofrecer de lo «mío» al otro; pero nunca carece de justicia, la cual lleva a dar al otro lo que es «suyo», lo que le corresponde en virtud de su ser y de su obrar. No puedo «dar» al otro de lo mío sin haberle dado en primer lugar lo que en justicia le corresponde. Quien ama con caridad a los demás, es ante todo justo con ellos. No basta decir que la justicia no es extraña a la caridad, que no es una vía alternativa o paralela a la caridad: la justicia es «inseparable de la caridad», intrínseca a ella. La justicia es la primera vía de la caridad [...]” BENEDICTO XVI.: Encíclica Caritas in veritate, n. 6.

27 "Chrysostomus: Ipse se transfigurat in pauperibus ut non erubescas dare modicum [...]" VILlanova, T: Concio 199: Dominica VI post Pentecosten. , In: Manrique L. (ed.). Obras completas $V$. Madrid 2012, p. 86.
} 
Para nuestro santo, la limosna no era solamente un favor o un mero acto de compasión con los más pobres, sino una cuestión de justa distribución de los bienes según la subsidiaridad. ${ }^{28}$

Ahora bien, en dichos tres textos ${ }^{29}$ podemos ver que el amor divino sirve como cauce, en la predicación de santo Tomás de Villanueva, para animar la gente a adoptar actitudes de solidaridad y de la misericordia.

El primer elemento de la caridad, basándose en la reflexión sobre la humanidad desde punto de vista de la creación, apunta hacia la solidaridad como virtud moral que guía al hombre hacia un vínculo sólido con el bien común. La solidaridad es aquí entendida como la suma de las actividades afectivas y efectivas dirigidas hacia el comportamiento responsable frente a los demás. El resultado de esta solidaridad es la actitud (actitudo) de compartir. Aquí, también, podemos identificar una doctrina primordial del principio de subsidiaridad. ${ }^{30}$

El segundo elemento de la teología de la caridad pertenece más bien a los campos de la cristología y de la soteriología. Representa un principio ejemplar por antonomasia, que se concreta en el último elemento (c.), el cual desvela en plenitud que el criterio inspirador de toda actividad humana no puede ser otro que el amor de Cristo. Aquí hay que subrayar que este tercer elemento de la teología de la caridad no se puede separar de la eclesialidad, que refleja el concepto de Iglesia como una sociedad orgánica y muestra que el motivo de toda la actividad cristiana no puede ser otro que el amor de Cristo.

Según Benedicto XVI, el texto fundamental para la acción caritativa de la Iglesia es el de la Segunda carta a los Corintios 5,14. Aunque santo Tomás de Villanueva nunca cita explícitamente las palabras "caritas Christi urget nos", podemos afirmar que están implícitamente presentes en su arte homilética. Santo Tomás de Villanueva dejaba bien claro que el amor de Dios es el impulso motivador de su búsqueda, que desemboca en la entrega solidaria a los demás. Las obras de la misericordia, como, por ejemplo, la limosna, fueron solamente una concreción de este principio.

\footnotetext{
${ }^{28}$ La subsidiaridad en BENEDICTO XVI. Cfr. BENEDICTO XVI.: Encíclica Deus caritas est, n. 26.

${ }^{29}$ Los textos son los referidos con respecto a la (a) justicia conmutativa [VILLANOVA, T: Concio 174: Dominica quarta post Pascha], (b) la solidaridad del Hijo de Dios con la humanidad [VILlANOVA, T: Concio 89: Feria quinta dominicae primae Quadragesimae, VILLANOVA, T: Concio 146: Feria IV Passionis] y (c) la solidaridad como respuesta de la praxis cristiana a la experiencia del amor de Dios [VILLANOVA, T: Concio 181: De foedere Burgis].

${ }^{30}$ BENEDICTO XVI.: Encíclica Deus caritas est, n. 26.
} 


\section{El amor que motiva la acción cristiana}

Santo Tomás de Villanueva, hablando del amor, distingue tres clases:

"El amor de Dios es de tres clases: natural, adquirido e infuso. Todas las cosas aman naturalmente a Dios como al bien supremo del que todo ser depende [...] Otra clase de amor de Dios es el adquirido por la contemplación de las criaturas, de los beneficios, de la grandeza, de la excelencia y la bondad de Dios [...] La tercera clase de amor de Dios es el amor infuso que Dios concede según su voluntad a los que le son fieles. Se le llama amor de caridad (o caridad), de acuerdo con las palabras del Apóstol: La caridad de Dios ha sido derramada en nuestros corazones por el Espíritu Santo que nos ha sido dado (Rom 5,5).,31.

Solamente a la tercera clase de amor llama "caritas". En línea con la teología monástica, aún vigente, pasa del amor a Dios al amor al prójimo. Solo este tipo de amor tiene que servir como motivación para la acción al prójimo: amar al prójimo por Dios y en Dios, solo así uno puede evitar caer en el amor posesivo. Santo Tomás lo expresa con las siguientes palabras, aludiendo a san Bernardo de Claraval ${ }^{32}$ :

"El amor que tiene por objeto al prójimo, si es verdadero amor de caridad, debe partir de Dios y acabar en Dios, pues Dios es el principio y el fin de la caridad; y si nace en el prójimo y termina en el prójimo, ese amor no es caridad. Un ejemplo de cómo Dios está en todas las cosas sería si al criado de un hijo tuyo, que está de viaje, le haces favores por consideración a tu hijo: no muestras con ello amor al criado, sino a tu hijo en el sirviente." ${ }^{33}$

Por lo tanto, una verdadera y dignificante motivación del trato con el prójimo no puede ser un amor posesivo.

\footnotetext{
31 "Triplex est dilectio Dei, scilicet naturalis, acquisita et infusa. Naturaliter omnia diligunt Deum tanquam supremum bonum, a quo totum esse dependet [...] Alia est dilectio acquisita ex contemplatione creaturarum,

beneficiorum, magnitudinis, excellentiae et bonitatis Dei [...] Alia est dilectio infusa quam Deus, prout vult, donat fidelibus suis, quae caritas nuncupatur, secundum illud Apostoli: Caritas Dei diffusa est in cordibus nostris per Spiritum Sanctum qui datus est nobis (Rom 5,5)“. VILlanOVA, T: Concio 207: Dominica XII post Pentecosten. In: Manrique L. (ed.). Obras completas $V$. Madrid 2012, p. 176

${ }^{32}$ Cfr. "Oportet ergo Deum diligi prius, ut in Deo diligi possit et proximus. Facit ergo etiam se diligi Deus, qui et captera bona facit." BERNARDUS CLARAVALLENSIS, De Diligendo Deo 8,25: PL 182, 989.

33 "Amor quo diligitur proximus, si vera caritas, esse debet a Deo et in Deum finiri debet, nam Deus principium et finis caritatis est, quod si ex proximo est et in proximum finit, amor ille non est caritas. Exemplum quomodo in omnibus Deus, de servo filii tui peregrinantis, cui propter filium facis beneficia: non tam servus, quam filius in servo diligitur." VILLANOVA, T: Concio 215: In dominicam XVII post Pentecosten. In: Manrique L. (ed.). Obras completas V. Madrid 2012, s. 332.
} 
"Te voy a decir la manera de que puedas amar a Dios con todo el corazón y a la vez amar todas las cosas. La solución está en amar a Dios en todas las cosas, y todas las cosas por Dios, y de ese modo, amas sólo a Dios. Así pues, el que ama a Dios en el prójimo y al prójimo por Dios, se ve que ama a solo Dios y su amor no está dividido, porque allí donde uno está en razón del otro, no hay más que uno solo. Ahora bien, si uno ama a su prójimo por otro motivo y no por Dios, aquí ya quita a Dios la parte del corazón que da al prójimo y ya no dirige a Dios toda. ${ }^{, 34}$

Comparando el pensamiento de santo Tomás de Villanueva con la encíclica Deus caritas est, podemos identificar varios puntos de convergencia. El primero, que el motivo principal de la acción humana no puede ser el amor posesivo, que busca sus ventajas, sino que tiene ser el amor oblativo, descendente. Según Benedicto XVI, no existe ninguna estructura justa sin la exigencia del amor, o la que haría el amor innecesario.

"La Iglesia nunca puede sentirse dispensada del ejercicio de la caridad como actividad organizada de los creyentes y, por otro lado, nunca habrá situaciones en las que no haga falta la caridad de cada cristiano individualmente, porque el hombre, más allá de la justicia, tiene y tendrá siempre necesidad de amor., 35

En segundo lugar, según santo Tomás de Villanueva el amor descendente es el elemento gracias al cual la justicia puede adquirir una nueva dimensión transcendental.

"La justicia una cierta regla que rige y ordena las relaciones del hombre con su prójimo en orden a la acción, a los honores y a los bienes temporales. Pero la perfección de la justicia está en perder de lo suyo y dárselo a otro, por lo que se dijo: Conviene que demos cumplimiento a toda justicia (Mt 3,15). Por consiguiente, la perfección de la justicia está en la humildad y en el amor, que no busca sus propios intereses (1Cor 13,5). ${ }^{, 36}$

\footnotetext{
34 "Modus iste est diligere Deum in omnibus et omnia propter Deum, et ecce solum Deum diligis. Qui ergo Deum diligit in proximo et proximum propter Deum, solum videtur Deum diligere, nec divisus est amor, quoniam ubi unum propter alterum, ibi tantum unum est. Si quis autem proximum alia ratione diligat et non propter Deum, hic iam de corde subtrahit Deo quod applicat proximo, nec totum amoris impetum reiicit in Deum, nec talis amor proximi caritas est, quoniam, ut ait Bernardus: Amor proximi si caritas sit, neque a proximo incipit, neque in proximo finitur; nec proximus caritatis principium est, neque finis.“ VILLANOVA, T: Concio 207:In dominicam XII post Pentecosten. In: Manrique L. (ed.). Obras completas V. Madrid 2012, s. 186.

${ }^{35}$ BENEDICTO XVI.: Encíclica Deus caritas est, n. 29.

36 "Iustitia regula quaedam, qua homo ordinate se habet ad proximum i agendis, in honoribus, in bonis temporalibus. Sed perfecto iustitiae est quando subtrahit de suo et dat alteri, ideo dicitur:
} 
Por el contrario, a diferencia de Benedicto XVI, santo Tomás de Villanueva no refleja suficientemente la complementariedad de ambos tipos del amor. Además, hay que recordar que no todas las conciones reflejan este señalado principio. Muchas veces, para conmover a sus oyentes hacia la acción solidaria, presentaba la visión de la retribución divina, la necesidad de rescatar sus pecados por medio de las buenas obras, que se corresponde con la praxis homilética de la época y con actitud de afrontar o evitar las corrientes de la reforma protestante.

"Nos debe mover a compasión la obligación que tenemos, bajo pena del infierno, de ayudar al que se encuentra en necesidad extrema. Está clamando contra nosotros la indigencia de los pobres y su clamor sube hasta la presencia de Dios. Uno tiene en abundancia de todo, y otro se está muriendo de hambre: ¿no pedirá Dios cuenta de esto?"37

\section{Teología del corazón y de la caridad}

Los autores de la tradición agustiniana se caracterizan por la theologia cordis, que es "una vía intermedia entre el puro intelectualismo y el voluntarismo extremo. Priman la voluntad, la gracia y el amor [...] un conocimiento afectivo, un conocimiento del corazón que conduce a la unión con Dios. ${ }^{38}$ En el proceso del discernimiento personal, nuestro santo pondera el diálogo interno que se realiza en la conciencia, que llama el rostro del alma. Para describir esta realidad utiliza siguiente exposición metafórica:

"¿Y cuál es la casa del alma? Sin duda la conciencia. Por la cara conocemos a las personas, la conciencia es conocida por Dios. Si la conciencia está limpia, hermosa está el alma. Dios no reconoce la lengua de una persona: Mirad, muchos van a venir diciendo: Señor, Señor, y el Señor a ellos: No os conozco (Mt 7,22). No conoce tampoco las manos, o sea, las obras exteriores, pues hay muchos que hacen obras externas muy llamativas y tampoco son conocidos por el Señor: Señor, ¿no es verdad que hemos profetizado en tu nombre? ¿Acaso no hemos hecho milagros? ¿No hemos expulsado demo-

\footnotetext{
Oportet nos implere omnem iustitiam. Humilitas ergo perfectio est iustitiae, et caritas quae non quaerit quae sua sunt." VILlANOVA, T.: Concio 198 Post Pestecosten. In: Manrique L. (ed.). Obras completas V. Madrid 2012, s. 74.

37 "Debet nos movere obligatio, qua tenemur sub poena inferni in extrema necessitate. Clamat adversum nos pauperum indigentia, et clamor eorum ascendit coram Deo. Alius abundat, alius fame perit, nunquid haec non requiret Deus?" VILLANOVA, T: Concio 199: Dominica VI post Pentecosten. , In: Manrique L. (ed.). Obras completas V. Madrid 2012, s. 88.

${ }^{38}$ Por. NORIEGA FERNÁNDEZ, Roberto. Ética para la reina. Isabel de Castilla y Martín de Córdoba, Madrid, 2014, s. 357-358.
} 
nios? ... Y él les responderá: Nunca os reconocí en aquellos tiempos en que os teníais por familiares e íntimos míos al hacer aquellos milagros. Yo no os reconocía: Alejaos de mí, ejecutores de maldad (Mt 25,41), pues yo sólo reconozco la pureza de conciencia, sólo la limpieza si va además acompañada por la unción de la cabeza." 39

Entonces, no son las obras externas, sino el corazón del hombre, el lugar en el que se deciden los valores de cada uno y donde se ve la belleza delante de Dios. Cuando santo Tomás de Villanueva comenta a los hipócritas del evangelio de Mateo (Mt 6,5-6), lo hace de la siguiente manera:

"La justicia de ellos eran escuetamente las obras; vuestra justicia tiene también en cuenta los afectos del corazón y las intenciones. Su justicia consiste en la apariencia exterior [...] Vuestra justicia está en la verdad a los ojos de Dios, no a los ojos de los hombres.., ${ }^{40}$

En el campo de la conciencia, puede el hombre descubrir el proyecto que el Creador había preparado para él, y así abrir la receptividad de su corazón a las necesidades de los demás.

"Ella nos hace muy semejantes a Dios, nos convierte en verdaderos hijos de Dios. Por eso recomendaba el Apóstol a los Colosenses: «Revestíos pues, escogidos que sois de Dios, santos y amados, de entrañas de compasión» (Col $3,12)$. No seáis duros, insensibles, secos como piedras. Esforzaos en ser atentos unos con otros, de modo que os afecte la necesidad ajena y os conmueva la miseria del prójimo." ${ }^{41}$

\footnotetext{
39 "Quae facies animae, nisi conscientia? Facie cognoscimus homines, conscientiam agnoscit Deus. Si munda est conscientia, pulchra est anima. Non agnoscit Deus hominis linguam. Ecce multi dicent: Domine, Domine, et Dominus eis: Nescio vos. Non agnoscit manus, id est, opera exteriora, nam multi praeclara opera exteriora faciunt qui etiam non agnoscuntur. Domine, nonne in nomine tuo prophetavimus? Nonne signa fecimus, daemonia eiicimus? Et dicet: Nunquam novi vos illo tempore quo credebamini ex operibus claris mei familiares et privati. Non vos agnoscebam: Discedite a me qui operamini iniquitatem, solam enim puritatem con scientiae agnosco, solam munditiam si adsit etiam unctio capitis." VILLANOVA, T: Concio 64: In feria IV Cinerum, In: Manrique L. (ed.). Obras completas II. Madrid 2011, s. 320.

40 "Iustitia illorum opera sola; attendit iustitia vestra cordis affectus etiam et cogitationes. Iustitia illorum in apparentia exterior [...] Iustitia vestra in veritate coram Deo, non coram hominibus." VILLANOVA, T: Concio 197: In dominicam V post Pentecosten. , In: Manrique L. (ed.). Obras completas V. Madrid 2012, s. 60-61.

41 "Nos Deo simillimos et filios veros Dei facit. Apostolus: Induite vos ergo, electi Dei, sancti et dilecti,

viscera misericordiae. Non sitis crudi, non duri, non sicci, sicut lapides. Conamini ut sitis ad invicem pii, ut tangat vos necessitas aliena et moveat vos miseria proximi. Vae duris et crudelibus! Apostolus inter alia crimina annumerat: Sine affectione, absque foedere, sine misericordia." VILlanOVA, T: Concio 199: Dominica VI post Pentecosten. , In: Manrique L. (ed.). Obras completas $V$. Madrid 2012, s. 88.
} 
Confrontando estas ideas de santo Tomás de Villanueva con el magisterio de Benedicto XVI en la encíclica Deus caritas est, podemos encontrar dos puntos concordes: (I) la refutación de la heteronomía en la actividad caritativa y (II) la importancia de la espiritualidad del corazón. Pero, a diferencia de santo Tomás de Villanueva, Benedicto XVI subraya más el carácter formativo de la actividad caritativa. $^{42}$

\section{Manifestación del amor}

Según Benedicto XVI la expresión de agapé indica la entrega del don recibi$\mathrm{do}^{43}$. Por su parte, para santo Tomás de Villanueva, quien tiene dones o alguna habilidad tiene el deber de ofrecerlos al servicio de los demás, de los pobres o de la comunidad.

"Y he infundido en el corazón de todos los hábiles cierta maestría para que lo ejecuten todo (Ex 31,6). Dígase lo mismo del artesano. Por lo tanto, tales personas deben poner su habilidad y sus conocimientos al ser vicio de los pobres y de la comunidad. Por ejemplo, un médico puede prestar una gran ayuda a los enfermos pobres. Lo mismo el farmacéutico, el perito en leyes y otros especialistas diversos." 44

La conciencia del don y de la vocación hacia el agapé debería guiar al hombre a superar su individualismo, la envidia y la avaricia, y a ofrecerse en servicio para promover el bien común. En este contexto resulta interesante la capacitad integrativa del amor infuso, sobrenatural (caritas), del que hablando santo Tomás de Villanueva. En sus homilías recuerda a sus oyentes que es precisamente la caridad (caritas) la que constituye la sociedad del bien, es decir, que la caridad (caritas) causa que uno comience a considerar el bien ajeno como propio.

\footnotetext{
${ }^{42} \mathrm{Cfr}$. "Por lo que se refiere al servicio que se ofrece a los que sufren, es preciso que sean competentes profesionalmente: [...] dichos agentes, además de la preparación profesional, necesitan también y sobre todo una «formación del corazón»: se les ha de guiar hacia ese encuentro con Dios en Cristo, que suscite en ellos el amor y abra su espíritu al otro, de modo que, para ellos, el amor al prójimo ya no sea un mandamiento por así decir impuesto desde fuera, sino una consecuencia que se desprende de su fe, la cual actúa por la caridad (cf. Ga 5, 6)." BENEDICTO XVI.: Encíclica Deus caritas est, n. 31.

${ }^{43}$ Cfr. BENEDICTO XVI.: Encíclica Deus caritas est, n. 7.

44 "Et in corde omnis eruditi posui sapientiam ut faciant cuncta (Ex 31,6). Unde tales debent sua arte vel scientia pauperibus et communitati prodesse, nam multum potest prodesse medicus infirmis pauperibus, pharmacopola, et legista, et alii artifices similiter." ."VILLANOVA, T: Concio 201: Dominica VIII post Pentecosten. , In: Manrique L. (ed.). Obras completas V. Madrid 2012, p. 122.
} 
"Guárdate, hermano, de la envidia espiritual, que es mucho peor que la temporal y carnal. ¿O es que sólo en tu celda deberá lucir el sol? ¿O quieres encerrar el sol en tu propiedad para que no alumbre a otros? ¿A ti qué te va si él prospera? Incluso, sí, te va mucho, porque en él recibes lo que no recibes en ti, y si hubiese en ti caridad, en su virtud habría gloria para ti, porque esto tiene de especial la caridad: que hace común lo propio, y propio lo común. Así que tuyo es, en virtud de la caridad, lo que tiene tu hermano." ${ }^{\circ 5}$

\section{Solidaridad y creatividad}

Uno de los puntos antropológicos básicos de partida es el concepto de hombre como imagen de Dios (imago Dei), por lo tanto, agraciado con la libertad y dignidad, llamado a amar. Teniendo en cuenta la originalidad de cada persona humana, y también la circunstancia en que la respuesta a esta vocación está naciendo en el corazón de cada uno, nos hace pensar en la creatividad a la hora de concretar el amor. ${ }^{46}$ En la obra de santo Tomás de Villanueva podemos identificar varios ejemplos de la multifacética manifestación del amor, lo cual remite a su carácter creativo. No se limita a ofrecer unas pocas obras de misericordia, sino que advierte que el verdadero amor no puede ser restringido por las circunstancias de la vida:

"Si la salvación dependiera de cualquier obra nuestra, quedaría excluido más de uno; muchísimos se exculparían diciendo que para ellos esa obra no era factible o fácil. Así, si hubieras decidido que nos salvaríamos dando limosnas, el pobre quedaría excluido; si era por el ayuno, se excluiría al enfermo; si con el trabajo, quedaría fuera el débil; si por el saber, excluiríamos al analfabeto; si por contemplación, se excluiría el labrador; si en la pobreza, quedaría fuera el rico. Y así sucesivamente. Sin embargo, del amor, ¿quién queda excluido?, ¿o quién está legítimamente excusado? A sabios e ignorantes, a ricos y pobres, niños y ancianos, a gentes de cualquier estado, sexo o edad, es común el amor. Nadie es viejo para amar, nadie es pobre para el amor. Pues, ¿quién no sabe o no puede amar? En todos los sitios en todos los tiempos el amor está al alcance de cualquiera." 47

\footnotetext{
45 "Cave, o frater, spiritualem invidiam, quae multo peior est quam temporalis et carnalis. Nunquid in sola tua cella lucebit sol? Et intra tuam hereditatem vis concludere solem ut aliis non luceat? Quid tua, si ille abundat? Immo, multum ad te, nam in illo accipis quod in te non accipis, et si adesset caritas, in illorum virtute esset tibi gloria; Hoc enim habet caritas, quod propria facit communia, et communia facit propria. Tuum igitur per caritatem est quod frater habet." VILlANOVA, T: Concio 43: Dominica in Septuagesima, In: Manrique L. (ed.). Obras completas II. Madrid 2011, p. 44.

${ }^{46}$ Cfr. BENEDICTO XVI.: Encíclica Deus caritas est, nn. 8 y 31.

47 "Sicut si in eleemosynarum largitione salvos nos esse voluisses, excluderetur egenus. Si in
} 
El siguiente indicador de la creatividad es la creación de estructuras solidarias $^{48}$. En este punto, santo Tomás de Villanueva intervenía con su voz crítica contra las estructuras injustas de su época, en concreto contra la injusta distribución y, sobre todo, la explotación de los bienes.

"¿Cuántos panes tenéis? Siete...; tenían también unos pececillos (Mc 8,5.7). Éstas eran las provisiones de los apóstoles: una sobria mesa. ¡Ah, los derroches de los ricos! ¡Cuántos gastos, y qué perdidamente! ¿A qué viene llenar sus estómagos para comida de los gusanos? Se produce pesadez de estómago, ¡natural! No tienes el estómago de un buey, la naturaleza nos hizo pequeños. ¿A qué viene ese derroche? (Mt 26,8). Si se moderara la comida, tendríamos suficiente para todos, y sobraría." ${ }^{49}$

Otro elemento muy importante fue la animación a sus oyentes para formar dichas estructuras caritativas:

"Tomad ejemplo del rico epulón (Lc 16,19-31): fue condenado porque no tuvo compasión; no por haber robado, sino por no haber dado. Y no esperéis a la extrema necesidad, cuando ya el pobre tenga la vela en la mano, porque en esos momentos no necesita vuestra comida, sino una sepultura. Es necesario que haya asilos para pobres en las ciudades; de no ser así, tendrían que hacer de asilo vuestras casas. En invierno, un hermano desnudo y enfermo, si no tiene una residencia, está en grave riesgo: el que tiene posibles, está obligado a darle hospedaje, porque se halla en peligro. Si no lo hacéis vosotros mismos, ayudad al menos a los centros de acogida y procurad que existan para que vosotros no os veáis obligados a hospedarlos y prestad ayuda a esos centros." 50

ieiunio, excluderetur aegrotus. Si in labore, excluderetur debilis. Si in doctrina, excluderetur idiota. $\mathrm{Si}$ in contemplatione, excluderetur agricola. $\mathrm{Si}$ in virginitate, excluderetur uxor. $\mathrm{Si}$ in paupertate, excluderetur dives, et ita de aliis. At vero ab amore quis excluditur aut quis legitime excusatur? Sapientibus et insipientibus, divitibus ac pauperibus, pueris et senibus, omni statui, omni sexui, omni aetati communis est amor. Nullus senex ad amorem, nemo pauper ad amandum. Quis enim amare nescit aut nequit?" VILLANOVA, T: Concio 212: In dominicam XVII post Pentecosten. , In: Manrique L. (ed.). Obras completas V. Madrid 2012, p. 266.

${ }^{48}$ Cfr. BENEDICTO XVI.: Encíclica Deus caritas est, n. 30-39.

49 "Quot panes habetis? qui dixerunt: Septem... Et habebant pisciculos paucos (Mc 8,5.7). Haec provisio apostolica: sobria mensa. Vae opulentiae divitum! O quot sumptus et quam perdite! Ad quid pro cibo vermium onerant stomachos? Fiunt aegritudines. Non habes bovis ventrem, natura parvos nos creavit. Ad quid perditio haec?, si cibus moderatus esset, sufficienter haberemus omnes, et superaret." VILLANOVA, T.: Concio 199: Dominica VI post Pestecosten. In: Manrique L. (ed.). Obras completas V, Madrid 2012, p. 94.

50 "Attendite exemplum in divite epulone; damnatus est quia non habuit misericordiam, non quia rapuit, sed quia non dedit. Nec extremam necessitatem, cum iam habet candelam in manu, nam tunc non eget cibo vestro sed sepultura. Necesse est in civitatibus esse hospitia pauperum, alias vestras domos oporteret esse hospitia. In hieme frater nudus et aeger, si non habet hospitium, periclitatur. Qui habet tenetur hospitari, quia in periculo est. Si non facitis, saltem favete 
Esta perspectiva se corresponde totalmente con lo expresado por Benedicto XVI, y santo Tomás la consideró como el núcleo central de la caridad de la Iglesia. Dice: "en la comunidad de los creyentes no debe haber una forma de pobreza en la que se niegue a alguien los bienes necesarios para una vida decorosa" ${ }^{51}$. Nuestro predicador presentaba el uso moderado de los bienes, las obras de la misericordia y la creación de diferentes formas de instituciones caritativas como el imperativo de la doctrina del Evangelio.

\section{CONCLUSIÓN}

En nuestra ponencia hemos presentado algunos acentos de la teología de la caridad de santo Tomás de Villanueva desde la perspectiva de la primera encíclica de Benedicto XVI. También hemos podido constatar que en la enseñanza de santo Tomás de Villanueva predomina una orientación práctica que refleja bien el contexto social de su época. El predicador muestra el modelo de encarnación del principio básico para un cristiano: creer en el amor de Dios. La inspiración por el amor es el principal elemento dinamizador de la vida cristiana. Junto con la caritas, que está inseparablemente unida con la gracia, se manifiesta también, la preocupación por el ideal de la perfección, que se refleja, sobre todo, en el esfuerzo por adquirir los méritos. Otros elementos que podríamos identificar en las Conciones son la identidad de los hijos de Dios y su relación con la comunidad eclesial. Todos ellos, claramente, desembocan en actitudes de solidaridad.

Santo Tomás de Villanueva hace de la caridad el fundamento para una justicia y una solidaridad humanizadoras.

A la luz de la encíclica de Benedicto XVI, y también de una teología renovada, nos parece muy actual el acento de santo Tomás de Villanueva sobre la dimensión dialógica de la conciencia humana, como también el ejemplo de la creatividad en las concreciones del amor.

Por lo tanto, podemos concluir que santo Tomás de Villanueva presenta, en el lenguaje del siglo XVI, uno de los núcleos centrales de la doctrina de la Iglesia católica. Aunque no le podemos llamar el fundador de la Doctrina Social de la Iglesia, sin duda alguna, podemos considerarlo como un representante de sus precursores.

hospitalibus et curate ut sint, ut vos non sitis obligati ad hospitandum, et adiuvate hospitalia." VILlanOVA, T.: Concio 199: Dominica VI post Pestecosten. In: Manrique L. (ed.). Obras completas $V$, Madrid 2012, p. 90.

${ }^{51}$ Cfr. BENEDICTO XVI.: Encíclica Deus caritas est, n. 20. 